\title{
Inovação e Interação Tecnológica na Escola de Enfermagem da USP
}

\section{Heloisa Helena Ciqueto Peres ${ }^{1}$, Maria Madalena Januário Leite ${ }^{2}$}

Com o objetivo de viabilizar a Formação, a Pesquisa e a Extensão em consonância com o desenvolvimento científico e tecnológico, a Escola de Enfermagem da Universidade de São Paulo (EEUSP) preocupou-se em investir no desenvolvimento de laboratório virtual de aprendizagem, por ser um espaço educativo para o ensino prático e para o desenvolvimento de ensino grupal e individual, além de ser centro de produção de conhecimento em enfermagem e suporte para a criação de produtos pedagógicos.

Dessa forma, a EEUSP criou um laboratório virtual de aprendizagem, localizado no terceiro piso da biblioteca da EEUSP, com uma área de $365 \mathrm{~m}^{2}$, não poupando esforços para equipá-lo com recursos que contemplem a modernidade tecnológica. Para tanto, inicialmente, obteve auxílio da Pró-Reitoria de Graduação com o Programa de valorização do Ensino de Graduação, de órgãos de fomento à pesquisa e apoio da disciplina de Telemedicina da Faculdade de Medicina da USP (FMUSP).

Assim, em 2004, foi realizada a primeira videoconferência na EEUSP, promovida pela disciplina de Tecnologia da Informação nos Processos de Trabalho na Saúde e na Enfermagem, do Programa de Pós Graduação em Enfermagem (PPGE), e, atualmente, com freqüência, os docentes utilizam a videoconferência para o ensino, a pesquisa, a extensão e, inclusive, para a participação de professores de instituições de ensino nacionais e internacionais nas defesas de dissertações de mestrado e de teses de doutorado.

No ensino de graduação, a primeira experiência foi junto à disciplina de Administração em Enfermagem que, desde 2005, semanalmente, por meio da videoconferência, promove interação entre os alunos, docentes e enfermeiros dos diferentes campos de estágio. Ainda, nessa disciplina, os alunos vivenciaram a estratégia da segunda opinião em enfermagem, junto aos enfermeiros do Hospital Universitário da USP, com o tema Processo de Tomada de Decisão, por meio de videoconferência e chats.

No âmbito da pesquisa, o Grupo de Estudos e Pesquisas de Tecnologia da Informação nos Processos de Trabalho em Enfermagem (GEPETE), vinculado ao CNPq (Conselho Nacional de Desenvolvimento Científico e Tecnológico), promoveu a primeira reunião da Sociedade Brasileira de Informática em Saúde (SBIS) por meio de videoconferência, usando videostreaming (transmissão de áudio e vídeos pela Internet em tempo real ou sob demanda).

Essas experiências, a consolidação da parceria com a disciplina de Telemedicina da FMUSP, a interação entre a equipe de Telemedicina e a equipe de Informática da EEUSP, a implementação do Programa Nacional de Reorientação da Formação de Profissional em Saúde (Pró-Saúde) dos Ministérios da Saúde e Educação, a capacitação tecnológica de docentes e de colaboradores da EEUSP, foram fatores essenciais para efetivar um espaço de aprendizagem virtual, constituindo-se no Centro de Estudos em Teleenfermagem - EEUSP (CETENF/ EEUSP).

Esse Centro, inaugurado em maio de 2007, é de natureza acadêmica, interdisciplinar, abrange instituições de ensino e organizações de saúde locais, nacionais e internacionais e tem como finalidade propiciar o uso das telecomunicações e das tecnologias computacionais na pesquisa, educação, gerenciamento e assistência em enfermagem.

Os objetivos do CETENF/EEUSP são: desenvolver pesquisas nas áreas de Teleenfermagem e Telessaúde; socializar produtos e processos de investigação, propiciando intercâmbio com centros de estudos e pesquisas nas áreas de Teleenfermagem e Telessaúde; desenvolver metodologias de educação à distância; promover a educação permanente; capacitar os docentes para a utilização da Teleenfermagem; promover a formação de uma rede de facilitadores/formadores em enfermagem e estabelecer parcerias entre instituições de ensino e de saúde, nacionais e internacionais.

O CETENF/EEUSP tem dois laboratórios virtuais de aprendizagem que permitem aos alunos o uso de videoconferência para discussão de casos clínicos com profissionais e professores que estejam distantes fisicamente. Nesses ambientes multidisciplinares de aprendizagem está sediado o Teleambulatório da EEUSP,

${ }_{1}^{1}$ Professora Doutora do Departamento de Orientação Profissional da EEUSP - ENO. Coordenadora do CETENF/EEUSP. São Paulo, SP, Brasil. hhcperes@usp.br ${ }^{2}$ Professora Associada do Departamento de Orientação Profissional da EEUSP - ENO. Coordenadora do CETENF/ EEUSP. São Paulo, SP, Brasil. marimada@usp.br 
equipado com 4 computadores da saúde que integra o Projeto de Teleenfermagem - segunda opinião formativa - em enfermagem e gestão e sustentabilidade na saúde, em parceria com a disciplina de Telemedicina da FMUSP, que objetiva debates, palestras, estudos de casos e a transmissões de técnicas e procedimentos específicos, junto às Unidades Básicas de Saúde do Estado de São Paulo.

Os laboratórios, também, oferecem objetos de aprendizagem para a compreensão de procedimentos e do corpo humano e, dentre eles, o Homem Virtual, conjunto de imagens dinâmicas criadas por computação gráfica 3D (www.projetohomemvirtual.org.br), bem como ambientes virtuais de aprendizagem baseados na Internet, que otimizam o aprendizado e aumentam a interatividade com os colegas, professores e enfermeiros.

Possui, ainda, uma Sala de Aula do Futuro que possibilita a mobilidade de alunos e professores e o compartilhamento de material educacional em tempo real, durante as aulas. Para isso, são empregados a tecnologia wireless (sem-fio), o videostreaming (transmissão de áudio e vídeos pela Internet sob demanda em tempo real) e a videoconferência. Em outro ambiente funciona uma estação de estudos e pesquisas, com a possibilidade de realização de webconference e de uso de telefonia baseada em Protocolos de Internet (Voz sobre IP ou VoIP) com tecnologia XML (eXtensible Markup Language). Serão analisadas as potencialidades desses equipamentos no compartilhamento de informações e de bancos de dados, com a finalidade de otimizar o trabalho de enfermagem. Uma das aplicações possíveis é o uso do telefone para permitir o rápido acesso ao estoque de medicamentos e ao cadastro de pacientes (com registro das prescrições e horários dos medicamentos, bem como da evolução de seu estado de saúde). $O$ telefone permite, ainda, a realização de audioconferências usando a Internet, sem custo das ligações.

Faz parte, também, do CETENF-EEUSP o Portal da Estação de Trabalho do Núcleo de Estudos e Pesquisa sobre Recursos Humanos da EEUSP (NEPRH/EE/USP), da Rede de Observatório de RH em Saúde, que integra as estações de trabalho da Organização Pan-Americana de Saúde (OPAS), onde se encontram a biblioteca virtual e a equipe de pesquisadores e suas respectivas produções. É possível o acesso às aulas e palestras em videostreaming, chats e fóruns.

Os projetos do CETENF/EEUSP têm resultado em dissertações e teses na área, além de outros estudos em desenvolvimento, com apoio da FAPESP (Fundação de Amparo à Pesquisa do Estado de São Paulo), do CNPq e OPAS.

Cabe destacar a participação no Projeto de Telemática e Telemedicina em Apoio à Atenção Primária, do Ministério da Saúde, desenvolvendo propostas de teleeducação interativa e de segunda opinião formativa especializada para atenção primária em enfermagem, junto ao Núcleo de Telessaúde de São Paulo. O principal objetivo dessas propostas é melhorar o atendimento da Atenção Básica no Sistema Único de Saúde, por meio da ampliação da capacitação da equipe de enfermagem que atua na Estratégia de Saúde da Família, utilizando a tecnologia para promover a educação permanente dos profissionais.

Diante do exposto, como coordenadoras do CETENF/EEUSP, pretendemos que esse Centro contribua para a implementação de uma educação corporativa on-line da equipe de enfermagem numa perspectiva emancipatória; para a construção do conhecimento coletivo em Telessaúde, Teleenfermagem e Informática em Enfermagem; para o desenvolvimento de novas metodologias de educação à distância, que proporcionarão a emergência de áreas de conhecimento e critérios inéditos de avaliação; e, principalmente, para a formação do aluno de enfermagem (graduação e pós-graduação) com competência para atuar no mundo contemporâneo de constantes mudanças, preparando os enfermeiros para os desafios tecnológicos na assistência à saúde, na gestão e na definição de referências éticas e científicas, priorizando a interação humana que acontece, especialmente, no trabalho da enfermagem. 